\title{
Denosumab might prevent periprosthetic bone loss after total hip and knee arthroplasties: a review
}

\author{
Jianda $\mathrm{Xu}^{1+}$, Huan $\mathrm{Li}^{2+}$, Yuxing Qu ${ }^{1 *}$, Chong Zheng ${ }^{1}$, Bin Wang ${ }^{1}$, Pengfei Shen ${ }^{1}, Z^{2}$ ikang Xie ${ }^{1}$, Kang Wei ${ }^{1}$, \\ Yan Wang ${ }^{1}$ and Jianning Zhao ${ }^{3^{*}}$
}

\begin{abstract}
Total hip arthroplasty and total knee arthroplasty are extensively used for the treatment of the end-stage degenerative joint diseases. Currently, periprosthetic bone loss is still the major cause of aseptic loosening, resulting in implant failures. Previous literature introduced some widely accepted protocols for the prevention and treatment of periprosthetic bone loss, but no guideline has been proposed. Denosumab, a human monoclonal immunoglobulin G2 (lgG2) antibody, can inhibit bone resorption by binding to the receptor activator of nuclear factor kappa-B ligand (RANKL). This article reviews the present findings and evidence concerning the effect of denosumab on the periprosthetic bone loss after total hip arthroplasty and total knee arthroplasty. Overall, the current evidence suggests that denosumab is a promising agent for the treatment of periprosthetic bone loss.
\end{abstract}

Keywords: Denosumab, Periprosthetic bone loss, Total hip/knee arthroplasty

\section{Introduction}

Both total hip arthroplasty (THA) and total kneearthroplasty (TKA) are common orthopaedic procedures for the treatment of the end-stage degenerative joint diseases. Currently, periprosthetic bone loss (PBL) remains the major cause of aseptic loosening that results in implant failures [1]. Previous literature reported some widely accepted protocols for preventing and treating PBL, but no guideline has been proposed [2-6].

Denosumab (Prolia), a human monoclonal immunoglobulin G2 (IgG2) antibody, can inhibit bone resorption by binding to the receptoractivator of nuclear factor kappa-B ligand (RANKL). It was initially engineered by Amgen and used for treating osteoporosis to increase

\footnotetext{
*Correspondence: quyuxing8848@163.com; zhaojianningnj@sina.com Xu Jianda and Li Huan are co-first author.

†Jianda Xu and Huan Li contributed equally to this work.

'Department of Orthopaedics, Changzhou Traditional Chinese Medical Hospital, Affiliated to Nanjing University of Traditional Chinese Medicine, 25 North Heping Road, Changzhou 213000, Jiangsu, China

${ }^{3}$ Department of Orthopaedics, Jinling Hospital, Nanjing 210002, Jiangsu, China

Full list of author information is available at the end of the article
}

bone mineral density (BMD). Denosumab increases bone mineral density by near-maximally reducing bone resorption [7].

PBL usually starts in the first postoperative year, and gradually slow down after 7 years $[2,3]$. To achieve a long-term survival of the implants, multiple medicines have been developed to treat PBL [4]. Bisphosphonates act on osteoclasts and inhibit periprosthetic bone resorption around the implant, but the effect on the local $\mathrm{BMD}$ is transient [5]. Alendronate can be used to attenuate the postoperative periprosthetic BMD, but its protective effect on bone density occurs after 6 months, missing the key period of bone resorption secondary to stress shielding happening 3 months after surgery [6].

This article reviews the current findings and evidence regarding the effect of denosumab on the PBL after THA and TKA.

\section{Why denosumab in THA and TKA?}

The receptor activator of nuclear factor $\kappa B$ (RANK) and its ligand (RANKL) signaling system play a critical role

(c) The Author(s). 2021 Open Access This article is licensed under a Creative Commons Attribution 4.0 International License, which permits use, sharing, adaptation, distribution and reproduction in any medium or format, as long as you give appropriate credit to the original author(s) and the source, provide a link to the Creative Commons licence, and indicate if changes were made. The images or other third party material in this article are included in the article's Creative Commons licence, unless indicated otherwise in a credit line to the material. If material is not included in the article's Creative Commons licence and your intended use is not permitted by statutory regulation or exceeds the permitted use, you will need to obtain permission directly from the copyright holder. To view a copy of this licence, visit http://creativecommons.org/licenses/by/4.0/. 
in the regulation of bone metabolism. It stimulates osteoclast formation and improves cell function and survival [8]. New osteoclasts are continuously recruited when the prosthetic loosening starts to worsen. Aspenberg et al. [9] suggested that targeting osteoclast recruitment via the RANKL system is a potential alternative for preventing periprosthetic loosening. Anti-RANKL agent exerts an effect comparable to high bisphosphonate doses in improving mechanical fixation of screws and fracture healing of cancellous bone [10]. The inhibiting process leads to a decreased bone resorption and increased bone density.

Denosumab, a human monoclonal immunoglobulin G2 (IgG2) antibody, selectively binds to RANKL. It works the same way as osteoprotegerin. Osteoprotegerin is an endogenous product of osteoblasts, and acts as a 'decoy receptor' of RANKL and modulates osteoclastic bone resorption [11]. The binding of denosumab with RANKL prevents the RANK from activation on the surface of osteoclasts and their precursors [12], thereby inhibiting bone resorption. Denosumab reduces bone resorption by $86 \%$ on average, which is higher than that of other anti-resorptive drugs [13].

Denosumab was initially engineered by Amgen. It is used to treat osteoporosis by increasing the BMD. After a recommended subcutaneous dosage (once every 6 months), the maximum serum concentration of denosumab is often achieved in a median of 10 days. Thereafter, the concentration slowly declines over a period of 3 to 5 months. Pharmacokinetically, it works in a non-linear and dose-dependent fashion [14]. Denosumab, when subcutaneously given, can improve BMD more effectively than bisphosphonate in patients with postmenopausal osteoporosis [15]. It rapidly increases the BMD and strength of osteoporotic cortical bones [16]. In addition, denosumab reduces the risk of fractures in postmenopausal women with osteoporosis. Compared with the placebo, it reduces the risk of hip fractures by $40 \%$ over a period of 3 years [13].

\section{Therapeutic efficacy of denosumab}

Periprosthetic bone remodelingdue to stress shielding is a biomechanical behavior post arthroplasty, especially 6 to 12 months after surgery. After THA, the periprosthetic BMD of the proximal femur drops from $15 \%$ to $40 \%$ in elderly patients with osteoporosis [17]. Denosumab can prevent PBL after THA. Especially in Gruen zone 7, the BMD can be increased by as much as 7\% (Table 1) [18]. Aro et al. (Table 1) [19] suggested that denosumab increases the BMD of proximal femur. It should be administered for 6 to 12 months after surgery, which allows the bone to respond locally to prevent stem migration. Nagoya et al. [18] believed that the post-TKA administration of denosumab could significantly prevent early PBL, and reduce periprosthetic tibial bone atrophy for up to 12 months. Murahashi et al. (Table 1) [20] confirmed that denosumab helped to attain a better early stability and prognosis by significantly reducing the PBL in the early postoperative period. Ledin et al. (Table 1) [21] found that denosumab reduced the early migration of the tibial component by minimizing the total point motion. It provided a better early and long-term stability of the implant.

\section{Potentials and unknowns Tolerability and safety}

A proven and well-established regime $(60 \mathrm{mg}$, once every 6 months) is well tolerated up to 10 years in postmenopausal women, even those with renal impairment [23]. BMD improvement still exists and no evidence of plateau is found even used after 10 years. No other denosumab-containing medications are used at the same time. The abdomen and upper arm or thigh are good places for subcutaneous injection. Coskun [24] analyzed the current data and concluded that denosumab was an effective therapeutic option to increase BMD and decrease the level of bone-turnover marker in patients with glucocorticoid-induced osteoporosis. No serious adverse event was reported. The denosumab is degraded into peptides and amino acids through hepatic, rather than renal, metabolism. The anti-fracture efficacy and dose are not significantly impacted by renal impairment [25].

Adverse events include injection site reaction and infection, hypocalcemia, cardiovascular issues, cancer, osteonecrosis of the jaw, etc. Among them, hypocalcaemia is a contraindication, but adequate intake of calcium and vitamin $\mathrm{D}$ can decrease the transient hypocalcemic effect, especially in patients with the conditions predisposing them to hypocalcemia. Although the RANKL is regularly expressed in some $\mathrm{T}$ lymphocytes, no immune dysfunction is found after denosumab therapy [7]. So far, cardiovascular and aortic calcification and glucose tolerance were reported, but further pharmacoepidemiological studies are warranted to evaluate its long-term efficacy and safety $[26,27]$.

\section{Duration and administration}

No consensus has been reached regarding the optimal duration of continuous denosumab therapy. However, the regular assessment of potential risks and benefits is needed. A world-wide, randomized, placebo-controlled trial involving 7868 women with postmenopausal osteoporosis showed that denosumab $(60 \mathrm{mg}$, twice yearly for 3 years) significantly reduced the risks of vertebral, nonvertebral, and hip fractures [13].

Denosumab discontinuation may bring a reversal effects on bone turnover and BMD. The anti-resorptive 


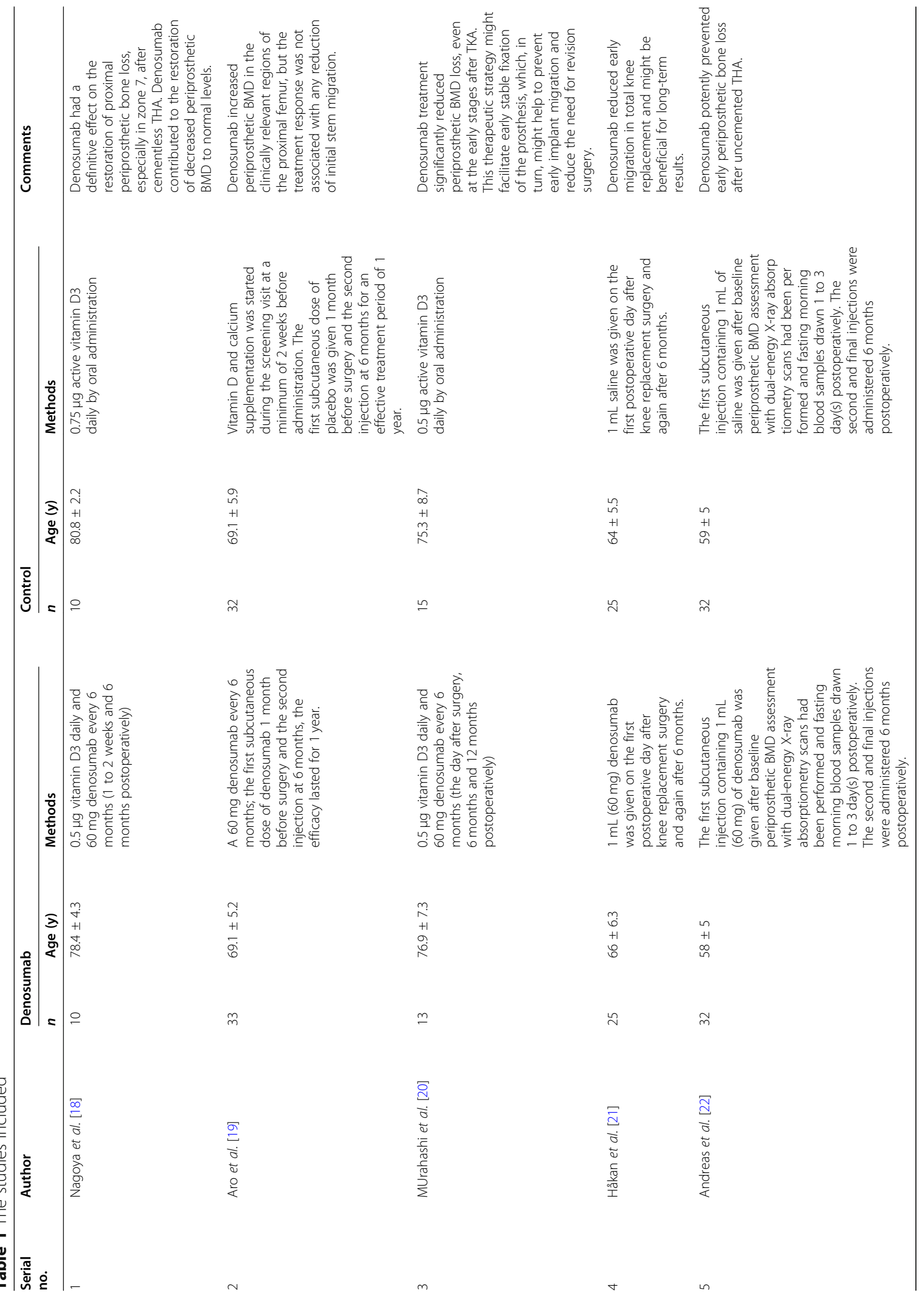


effects disappear quickly after the treatment withdrawal. Nyström et al. (Table 1) [22] conducted a prospective randomized controlled trial. They found that denosumab prevented the early bone resorption around the implants. However, they also found that the biochemical markers of bone metabolism decreased in the first year and rebounded after 2 years. The retardation effect of bone loss lasted only when treatment persisted (Table 1). The authors concluded that denosumab persistently preserves the periprosthetic BMD after uncemented THA. The rebound effect of bone metabolism markers and the loss of gained BMD were also found in the postmenopausal women who suspended denosumab 3 days to 6 months after surgery [28].

A potential risk of multiple vertebral fractures does exist. And patients are not advised to delay or omit denosumab doses due to the relatively poor prognosis of vertebroplasty. The conclusions are based on the arbitrary cut-off of 2 years [29]. Considering the rebound fractures, the European Menopause and Andropause Society recommends that other anti-resorptive drugs be used after denosumab discontinuation, but the protocol is not supported by solid evidence [30].

\section{Combination or sequential administration}

In patients with postmenopausal osteoporosis, switching to denosumab was associated with higher BMD in the spine and hip than those who continued alendronate after 12 months [31]. The same phenomenon was also found with use of ibandronate [32] and zoledronic acid [15]. Moreover, denosumab increases BMD with the anabolic agent teriparatide in women with postmenopausal osteoporosis [33]. An anabolic agent combined with bone resorption inhibitor may be a promising approach. However, whether it will translate to a higher reduction of fracture risk needs further pharmacological and clinical studies in the future.

\section{Conclusions}

Currently, the overall evidence suggests that denosumab is promising in treating PBL. Sufficiently-sized and longterm randomized controlled trials are needed to find the optimal administration routes and potential side effects in THA and TKA arthroplasties.

\section{Abbreviations \\ THA/TKA: Total hip/knee arthroplasty; IgG2: Immunoglobulin G2; RANK $\mathrm{L}$ : Receptor activator of nuclear factor kappa-B ligand; BMD: Bone mineral density; OPG: Osteoprotegerin; RANK: Receptor activator of NF-KB; RANK $\mathrm{L}$ : Receptor activator of nuclear factor $\mathrm{KB}$ ligand}

\section{Acknowledgements}

None.

\section{Authors' contributions}

ZC, WB, SP, XZ, WK and WY undertook data management and analysis. The author(s) read and approved the final manuscript.

\section{Funding}

The project was supported by a grant from the Changzhou Science and Technology Bureau (No. 20180041).

\section{Availability of data and materials}

Data sharing not applicable to this review as no datasets were generated or analyzed during this review.

Ethics approval and consent to participate

Not applicable.

\section{Consent for publication}

All authors have read and approved the final manuscript.

\section{Competing interests}

The authors declare that they have no competing interests.

\section{Author details}

${ }^{1}$ Department of Orthopaedics, Changzhou Traditional Chinese Medical Hospital, Affiliated to Nanjing University of Traditional Chinese Medicine, 25 North Heping Road, Changzhou 213000, Jiangsu, China. ²Department of Arthroplasty, The First People's Hospital of Changzhou, Changzhou 213003, China. ${ }^{3}$ Department of Orthopaedics, Jinling Hospital, Nanjing 210002, Jiangsu, China.

Received: 7 June 2020 Accepted: 18 January 2021

Published online: 12 April 2021

\section{References}

1. West CR, Bedard NA, Duchman KR, Westermann RW, Callaghan JJ. Rates and risk factors for revision hip arthroscopy. lowa Orthop J. 2019;39(1):95-9.

2. Tran $P$, Zhang BX, Lade JA, et al. Periprosthetic bone remodeling afternovel short-stem neck-sparing total hip arthroplasty. J Arthroplast. 2016:31:2530-5.

3. Li MG, Nilsson KG. The effect of the preoperative bone quality on the fixation of the tibial component in total knee arthroplasty. J Arthroplast. 2000;15:744-53.

4. Hilding M, Aspenberg P. Postoperative clodronate decreases prosthetic migration: 4-year follow-up of a randomized radiostereometric study of 50 total knee patients. Acta Orthop. 2006;77:912-6.

5. Muren O, Akbarian E, Salemyr M, et al. No effect of risedronate onfemoral periprosthetic bone loss following total hip arthroplasty. A4-year follow-up of 61 patients in a double-blind, randomizedplacebo-controlled trial. Acta Orthop. 2015;86(5):569-74

6. Jaroma AV, Soininvaara TA, Kröger H. Effect of one-year post-operative alendronate treatment on periprosthetic bone after total knee arthroplasty. A seven-year randomised controlled trial of 26 patients. Bone Joint J. 2015; 97-B:337-45.

7. McClung MR, Lewiecki EM, Cohen SB, et al. Denosumab in postmenopausal women with low bone mineral density. N Engl J Med. 2006;354(8):821-31.

8. Kostenuik PJ. Osteoprotegerin and RANKL regulate bone resorption, density, geometry and strength. Curr Opin Pharmacol. 2005;5(6):618-25.

9. Aspenberg P, Agholme F, Magnusson P, Fahlgren A. Targeting RANKL for reduction of bone loss around unstable implants: OPG-Fc compared to alendronate in a model for mechanically induced loosening. Bone. 2011; 48(2):225-30.

10. Bernhardsson M, Sandberg O, Aspenberg P. Anti-RANKL treatment improves screw fixation in cancellous bone in rats. Injury. 2015:46:990-5.

11. Rochette L, Meloux A, Rigal E, et al. The role of osteoprotegerin in vascular calcification and bone metabolism: the basis for developing new therapeutics. Calcif Tissue Int. 2019;105(3):239-51.

12. Kostenuik PJ, Nguyen HQ, McCabe J, et al. Denosumab, a fullyhuman monoclonal antibody to RANKL, inhibits bone resorptionand increases BMD in knock-in mice that express chimeric (murine/human) RANKL. J Bone Miner Res. 2009;24(2):182-95.

13. Cummings SR, San Martin J, McClung MR, et al. Denosumab for prevention of fractures in postmenopausal women with osteoporosis. N Engl J Med. 2009;361 (8):756-65.

14. Deeks ED. Denosumab: A Review in Postmenopausal Osteoporosis. Drugs Aging. 2018;35(2):163-73. 
15. Miller PD, Pannacciulli N, Brown JP, et al. Denosumab orzoledronic acid in postmenopausal women with osteoporosis previously treated with oral bisphosphonates. J Clin Endocrinol Metab. 2016;101(8):3163-70.

16. Genant HK, Libanati $C$, Engelke $K$, et al. Improvements in hip trabecular, subcortical, and cortical density and mass in postmenopausal women with osteoporosis treated with denosumab. Bone. 2013;56(2):482-8.

17. Gibbons CE, Davies AJ, Amis AA, et al. Periprosthetic bone mineral density changes with femoral components of differing design philosophy. Int Orthop. 2001;25:89-92.

18. Nagoya S, Tateda K, Okazaki S, Kosukegawa I, Shimizu J, Yamashita T. Restoration of proximal periprosthetic bone loss by denosumab incementless total hip arthroplasty. Eur J Orthop Surg Traumatol. 2018;28(8): $1601-7$.

19. Aro HT, Nazari-Farsani S, Vuopio M, Löyttyniemi E, Mattila K. Effect of denosumab on femoral periprosthetic BMD and early femoral stem subsidence in postmenopausal women undergoing cementless total hip arthroplasty. JBMR Plus. 2019;3(10):e10217.

20. Murahashi Y, Teramoto A, Jimbo S, et al. Denosumab prevents periprosthetic bone mineral density loss in the tibial metaphysis in total knee arthroplasty. Knee. 2020;27(2):580-6.

21. Ledin $H$, Good L, Aspenberg P. Denosumab reduces early migration in total knee replacement. Acta Orthop. 2017:88(3):255-8.

22. Nyström A, Kiritopoulos D, Ullmark G, et al. Denosumab prevents early periprosthetic bone loss after uncemented total hip arthroplasty: results from a randomized placebo-controlled clinical trial. J Bone Miner Res. 2020; 35(2):239-47.

23. Boonen S, Adachi JD, Man Z, et al. Treatment with denosumabreduces the incidence of new vertebral and hip fractures inpostmenopausal women at high risk. J Clin Endocrinol Metab. 2011;96(6):1727-36.

24. Coskun BI. Denosumab in the treatment of glucocorticoid-induced osteoporosis. Rheumatol Int. 2018;38(11):1975-84.

25. Jamal SA, Ljunggren O, Stehman-Breen C, et al. Effects ofdenosumab on fracture and bone mineral density by level ofkidney function. J Bone Miner Res. 2011;26(8):1829-35.

26. Lasco A, Morabito N, Basile G, et al. Denosumab inhibition of RANKL and insulin resistance in postmenopausal women with osteoporosis. Calcif Tissue Int. 2016:98(2):123-8.

27. Samelson EJ, Miller PD, Christiansen C, et al. RANKL inhibition with denosumab does not influence 3-year progression of aortic calcification or incidence of adverse cardiovascular events in postmenopausal women with osteoporosis and high cardiovascular risk. J Bone Miner Res. 2014;29(2):450-7.

28. Bone $\mathrm{HG}$, Bolognese $\mathrm{MA}$, Yuen $\mathrm{CK}$, et al. Effects of denosumab treatment and discontinuation on bone mineral density and bone turnover markers in postmenopausal women with low bone mass. J Clin Endocrinol Metab. 2011;96(4):972-80.

29. Anastasilakis AD, Polyzos SA, Makras P, Aubry-Rozier B, Kaouri S, Lamy O. Clinical features of 24 patients with rebound-associated vertebral fractures after denosumab discontinuation: systematic reviewand additional cases. Bone Miner Res. 2017;32(6):1291-6.

30. Anagnostis P, Paschou SA, Mintziori G, et al. Drug holidays from bisphosphonates and denosumab in postmenopausal osteoporosis: EMAS position statement. Maturitas. 2017;101:23-30.

31. Kendler DL, Roux C, Benhamou CL, Brown JP, Lillestol M, Siddhanti S, et al. Effects of denosumab on bone mineral density andbone turnover in postmenopausal women transitioning from alendronatetherapy. J Bone Miner Res. 2010;25:72-81.

32. Recknor C, Czerwinski E, Bone HG, Bonnick SL, Binkley N, Palacios S, et al. Denosumab compared with ibandronate in postmenopausal women previously treated with bisphosphonate therapy: arandomized open-label trial. Obstet Gynecol. 2013;121:1291-9.

33. Leder BZ, Tsai JN, Uihlein AV, Wallace PM, Lee H, Neer RM, et al. Denosumab and teriparatide transitions in postmenopausal osteoporosis (the DATA-Switch study): extension of a randomised controlled trial. Lancet. 2015;386:1147-55.

\section{Publisher's Note}

Springer Nature remains neutral with regard to jurisdictional claims in published maps and institutional affiliations.

\section{Ready to submit your research? Choose BMC and benefit from:}

- fast, convenient online submission

- thorough peer review by experienced researchers in your field

- rapid publication on acceptance

- support for research data, including large and complex data types

- gold Open Access which fosters wider collaboration and increased citations

- maximum visibility for your research: over $100 \mathrm{M}$ website views per year

At $\mathrm{BMC}$, research is always in progress.

Learn more biomedcentral.com/submissions 